\title{
CXC chemokine receptor 4 regulates neuronal migration and axonal pathfinding in the developing nervous system: implications for neuronal regeneration in the adult brain
}

\author{
Ralf Stumm and Volker Höllt \\ Institute of Pharmacology and Toxicology, Otto-von-Guericke-University Magdeburg, Leipziger Strasse 44, 39120 Magdeburg, Germany \\ (Requests for offprints should be addressed to R Stumm; Email: ralf.stumm @medizin.uni-magdeburg.de)
}

\begin{abstract}
Chemotactic cytokines (chemokines) are small secreted proteins that control leukocyte trafficking in immune organs. Chemokines which are induced in the brain during conditions of inflammation play a role in the local immune response. Recently, it has been established in the rodent brain that distinct chemokines and chemokine receptors are constitutively expressed by neurons and that these chemokines modulate neuronal functions. The CXC motif chemokine stromal cellderived factor-1 (SDF-1), CXCL12 together with its cognate receptor CXCR4 represents the best-characterized neuronal chemokine system. Transwell migration assays with neuronal precursors, pharmacological manipulation of CXCR4 signaling in embryonic brain explants, and histochemical studies of SDF-1- or CXCR4-deficient mouse embryos provide proof that SDF-1 directs neuronal migration and axonal pathfinding in the developing nervous system. In the adult brain, SDF-1 is thought to influence neurogenesis as well as recruitment of brain resident and non-resident circulating cells toward sites of lesion. The present review summarizes patterns and functions of the SDF-1/CXCR4 system in the rodent brain with a focus on the developing and adult cerebral cortex.
\end{abstract}

Journal of Molecular Endocrinology (2007) 38, 377-382

\section{CXC chemokine receptor 4(CXCR4) regulates neuronal migration and axonal pathfinding}

The identification of molecules guiding neuronal migration and circuit formation during brain development is crucial for our understanding of brain function. Moreover, unraveling the molecular mechanisms establishing plasticity in the developing brain might help to define factors restraining and factors promoting regeneration after damage in the mature brain. A variety of molecules including chemotactic cytokines (chemokines) have been identified which guide directed migration of neurons from specialized neurogenic regions to their final destination. Stromal cell-derived factor-1 (SDF-1) has emerged as an indispensable chemoattractant for migratory neurons constituting the cerebellum, dentate gyrus, cerebral cortex, dorsal root ganglia, and nuclei in the brainstem in rodents (Ma et al. 1998, Zou et al. 1998, Klein et al. 2001, Bagri et al. 2002, Lu et al. 2002, Stumm et al. 2003, Belmadani et al. 2005, Odemis et al. 2005, Vilz et al. 2005, Borrell \& Marin 2006). When arrived at their destination, neurons extend dendrites to characteristic regions and grow axonal processes to selective target tissues and cells. Evidence that CXCR4 regulates axonal guidance has been provided in motor neurons, retinal ganglion cells, primary afferents, and sympathetic neurons (Chalasani et al. 2003, Lieberam et al. 2005). Thus, the SDF-1/CXCR4 system continues to influence the development of neurons during and after the migratory process. Notably, in addition to neuronal development, CXCR4 influences also the migration and survival of oligodendrocytes (Dziembowska et al. 2005).

First evidence that SDF-1 is required for brain development was presented in 1998, when abnormal cerebellar development was discovered in SDF-1- and CXCR4-deficient embryos (Ma et al. 1998, Zou et al. 1998). Subsequently, SDF-1 was shown to be highly expressed in the leptomeninx and to represent the major attractant for external germinal layer cells in the developing cerebellum (Klein et al. 2001, Tham et al. 2001, Reiss et al. 2002, Zhu et al. 2002). The concept that mesenchymal cells influence the development of a juxtaposed neuronal structure by secreting SDF-1 was confirmed in the cerebral cortex (Stumm et al. 2003, Borrell \& Marin 2006), dentate gyrus (Lu et al. 2002), and motor axons (Lieberam et al. 2005).

DOI: 10.1677/JME-06-0032 Online version via http://www.endocrinology-journals.org 


\section{SDF-1 regulates migration and function of hypothalamic neurons}

Recently, expression of SDF-1 by the nasal mesenchyme in an increasing rostral to caudal gradient has been proposed to guide gonadotropin-releasing hormone (GnRH)-expressing neurons and possibly olfactory axons from the nasal cavity toward the telencephalon (Schwarting et al. 2006). This is based on the finding that, in CXCR4-deficient mice, the long-ranged migration of the majority of GnRH-expressing neurons from the vomeronasal organ to the basal telencephalon and hypothalamus is impaired. In addition, growth of the olfactory nerve appears to be partially affected (Schwarting et al. 2006). A role of CXCR4 in the growth of olfactory nerve fibers is consistent with our own unpublished observations of intense CXCR4-like immunoreactivity in olfactory axons. Thus, SDF-1 and CXCR4 represent novel candidate genes potentially involved in the clinical and neuroendocrine phenotype of Kallman's syndrome, which is characterized by the failure of GnRH-expressing neurons to migrate toward the hypothalamus, hypogonadotropic hypogonadism, and complete or partial loss of the sense of smell (Schwarting et al. 2006). The importance of CXCR4 for the development of the human nervous system has yet to be demonstrated, even though structure and function of CXCR4 are conserved during vertebrate development and expression of CXCR4 by human hippocampal neurons has been reported (van der Meer et al. 2000, Braun et al. 2002).

Recent neuroanatomical and functional analyses in rats have provided compelling evidence for a role of the SDF-1/CXCR4 system in regulation of neuroendocrine functions in the adult brain. In particular, colocalization of SDF-1 and CXCR4 in arginine vasopressin (AVP)containing neurons in the supraoptic nucleus and paraventricular nucleus as well as AVP-containing projections to the neurohypophysis was shown (Banisadr et al. 2002, 2003). Moreover, electrophysiological recordings of neurons in the supraoptic nucleus (SON) demonstrated that SDF-1 regulates electrical activity and AVP release of AVP neurons through CXCR4 (Callewaere et al. 2006).

\section{Links between CXCR4 and neuronal morphogenesis}

Which properties allow the SDF-1/CXCR4 system to control neuronal migration and morphogenesis? Changes in neuronal shape require rearrangements of the actin and microtubule cytoskeleton (Tanaka \& Sabry 1995). In cerebellar granule cells, SDF-1 dosedependently regulates the balance between enhanced and suppressed axon outgrowth via a Rho-dependent pathway (Arakawa et al. 2003). The family of Rho-GTPases links extracellular signals to changes in the actin cytoskeleton and modulates motility and guidance of growth cones which are found at the leading tip of migrating neurons and extending axons (Dickson 2001). In accordance with the regulatory role of cyclic nucleotides in growth cone responsiveness to guidance cues (Dickson 2002), SDF-1 has been shown to reduce the repellent activity of semaphorin $3 \mathrm{~A}$, semaphorin $3 \mathrm{C}$, and slit-2 by modulating the cAMP level (Chalasani et al. 2003). Early studies of cortical progenitors showed that chemoattraction by SDF-1 requires activation of extracellular signal-regulated kinases $1 / 2$ and a pertussis toxinsensitive Gi protein (Lazarini et al. 2000). In hippocampal neurons, SDF-1 reduces axonal outgrowth but stimulates axonal branching without affecting other neurites (Pujol et al. 2005), and it has been proposed that differential trafficking of CXCR4 in dendritic and axonal membrane subdomains might be involved in the axon-selective effect of SDF-1 in these neurons (Baudouin et al. 2006).

Given the large size (89 amino acids for the unprocessed mouse SDF-1 precursor), susceptibility to enzymatic degradation, and binding to the extracellular matrix of the SDF-1 protein (McQuibban et al. 2001), it is most likely that SDF-1-secreting cells influence CXCR4expressing neuronal structures in a spatially confined paracrine manner. Consistently, SDF-1 is highly expressed along the migration pathways of CXCR4-expressing neurons and the trajectories of CXCR4-expressing axons in neuronal tissues, where neuronal migration and axonal growth depend on CXCR4 (Klein et al. 2001, Bagri et al. 2002, Lu et al. 2002, Chalasani et al. 2003, Stumm et al. 2003, Belmadani et al. 2005, Lieberam et al. 2005, Vilz et al. 2005). Since immune cells which are attracted by low concentrations of SDF-1 can be repulsed by high concentrations of SDF-1 (Poznansky et al. 2000), a high SDF-1 content along a neuronal migration route might cause attraction or repulsion depending on the local SDF-1 concentration gradient. In non-neuronal cells, rapid agonist-promoted internalization, lysosomal sorting, ubiquitination, and degradation of CXCR4 have been shown (Marchese \& Benovic 2001). If a similar mechanism existed in migrating neuronal cells as suggested (Baudouin et al. 2006), persistent SDF-1/ CXCR4 signaling would require high-level mRNA expression and synthesis of CXCR4 to prevent rapid CXCR4 desensitization and downregulation. Conversely, a reduction of CXCR4 gene expression would result in a rapid loss of responsiveness to SDF-1.

\section{Influence of CXCR4 on Cajal-Retzius cells in the cerebral cortex}

Dynamics and modes of neuronal migration have been extensively studied in the cerebral cortex and numerous reviews on cortical development are available 
(Marin \& Rubenstein 2001, Kriegstein \& Noctor 2004, Metin et al. 2006). This review summarizes the current knowledge about SDF-1 and CXCR4 in the cortex and discusses putative functions of this system in cortical development and degeneration/regeneration. At the early developmental stage, the cortex consists of the ventricular zone and preplate, which is localized at the surface of the telencephalic vesicles. Neurons are born in the ventricular zone and postmitotic neurons are selectively placed in the preplate (Kriegstein \& Noctor 2004). Cajal-Retzius cells constitute a transiently existing subpopulation of preplate neurons which remain in the superficial cortical layer (marginal zone, layer I) during further cortical development (Soriano \& Del Rio 2005). Cajal-Retzius cells are the preponderant source of the extracellular matrix protein reelin, which is indispensable for cortical and hippocampal development (Alcantara et al. 1998, Forster et al. 2006). In addition, these neurons are an important component of early cortical network activity and it was suggested that Cajal-Retzius cells modulate cortical maturation (Soriano \& Del Rio 2005).

CXCR4 is highly expressed in Cajal-Retzius cells (Stumm et al. 2003, Tissir et al. 2004, Yamazaki et al. 2004, Borrell \& Marin 2006, Paredes et al. 2006). The presence of SDF-1 in the meninges covering the cortex (Tham et al. 2001) suggests a paracrine SDF-1/CXCR4mediated influence of mesenchymal meningeal cells on Cajal-Retzius cells. PCR-based identification of SDF-1 transcripts in Cajal-Retzius cells (Yamazaki et al. 2004) points to an autocrine SDF-1/CXCR4-mediated modulation of Cajal-Retzius cell function. Initial studies in SDF-1- and CXCR4-deficient mice performed to test the hypothesis that radial migration of Cajal-Retzius cells from the cortical ventricular zone toward the cortical surface is mediated by meningeal SDF- 1 , found a reduction in the number of Cajal-Retzius cells. However, a large proportion of Cajal-Retzius cells was correctly placed (Stumm et al. 2003). It was therefore proposed that SDF-1 might act on Cajal-Retzius cells as a trophic factor rather than as a guidance cue. At that time, however, the origin and migration routes of CajalRetzius cells were unclear. Recently, the origin of a substantial fraction of Cajal-Retzius cells in the cortical hem (the caudomedial edge of the cortex) was identified and it is now clear that Cajal-Retzius cells show little radial migration but disperse tangentially in the marginal zone (Takiguchi-Hayashi et al. 2004, Soriano \& Del Rio 2005). The possibility that SDF-1 regulates Cajal-Retzius cell migration has been revisited and the authors provide compelling evidence that meningeal SDF-1 is indispensable for tangential migration of hem-derived Cajal-Retzius cells (Borrell \& Marin 2006). Consistently, using p73 (a homolog of the tumor suppressor p53) as a Cajal-Retzius cell marker, ectopic placement of some Cajal-Retzius cells could be demonstrated in CXCR4-deficient mice (Paredes et al. 2006). Heterogeneity of Cajal-Retzius cells with respect to origin and responsiveness to attractants other than SDF-1 might explain that a substantial proportion of Cajal-Retzius cells is correctly placed in CXCR4deficient mice.

\section{Does CXCR4 regulate radial migration of pyramidal cells?}

As cortical development continues, new neurons become placed within the preplate. By forming the cortical plate, these neurons split the preplate into the marginal zone at the surface of the cortex and the subplate below the cortical plate. The preponderant neuron in the cortical plate is the pyramidal cell. These glutamatergic projection neurons originate close to the ventricle in the cortex. They use glial cells for guidance during radial outward migration, and, when reaching the marginal zone, become placed on the top of earliergenerated pyramidal cells (Kriegstein \& Noctor 2004). Immunohistochemical and in situ hybridization analyses of the rat cortex during the period of cortical plate development did not detect CXCR4 in radially migrating neurons or the cortical ventricular zone (Stumm et al. 2003). It is therefore unlikely that CXCR4 regulates pyramidal cell migration directly. Nevertheless, future analyses of the cortex of SDF-1and CXCR4-deficient embryos will have to address whether radial glia morphology, precursor proliferation rate, and birth-date-dependent layering of pyramidal cells are intact.

\section{CXCR4 regulates tangential migration of cortical GABAergic neurons}

Albeit much smaller in number than pyramidal cells, GABAergic neurons represent the second major neuronal population in the cortex. The vast majority of cortical GABAergic neurons originate in the ventricular zone of the medial, lateral, and caudal ganglionic eminences which are localized in the ventral telencephalon and form the primordia of the basal ganglia (Marin \& Rubenstein 2001, Metin et al. 2006). After being generated close to the ventricle in the medial ganglionic eminence, GABAergic neurons migrate tangentially toward the cortical boundary and, after entering the dorsal telencephalon, continue their tangential migration on the top of the cortical plate (in the marginal zone) or below the cortical plate (in the intermediate zone/subventricular zone (IZ/ SVZ)). To integrate into the cortical plate, GABAergic precursors descend from the marginal zone or ascend radially from the IZ/SVZ (Metin et al. 2006). 
Evidence that CXCR4 influences the migration of cortical GABAergic neurons comes from in situ hybridization studies in CXCR4- and SDF-1-deficient embryos showing a perturbed distribution of GABAergic neurons (Stumm et al. 2003). The most obvious defect is present in the marginal zone, where neurons expressing the GABAergic marker; glutamic acid decarboxylase (GAD) are clustered at high density in wild types but are underrepresented in the mutant mice. In the deep cortical layers of the mutants, GADexpressing cells are aberrantly distributed as well. Since CXCR4 is expressed in GABAergic precursors populating both tangential migration pathways and SDF-1 attracts precursors isolated from the ventral telencephalon, SDF-1 is likely to regulate the migration of GABAergic precursors directly (Stumm et al. 2003).

\section{SDF-1 is expressed along the migration pathways of GABAergic precursors}

To understand how the dynamics of the patterns of SDF-1 and those of tangential migration might be connected, the marginal zone and the area below the cortical plate will be discussed separately. In the marginal zone, CXCR4-expressing GABAergic precursors face a high SDF-1 content in the adjacent meninges (Tham et al. 2001, Stumm et al. 2003, Tissir et al. 2004). It is therefore likely that tangential migration of these GABAergic neurons is supported by SDF-1 derived from mesenchymal meningeal cells in a similar way as that of hem-derived Cajal-Retzius cells (Borrell \& Marin 2006). Eventually, loss of the SDF-1 signal might enable the tangentially migrating neurons to descend toward the cortical plate. Since meningeal SDF-1 expression shows little change during the period of tangential migration, SDF-1/CXCR4 signaling might rather be terminated by desensitizing CXCR4. This could be achieved by reduced CXCR4 gene expression in combination with ligand-induced internalization and degradation of the CXCR4 protein (Marchese \& Benovic 2001).

Below the cortical plate, the situation is fundamentally different. SDF-1 is expressed initially in a confined area dorsal to the boundary of dorsal and ventral telencephalon just when ventrally derived CXCR4expressing neurons begin to invade this region. Subsequently, SDF-1 expression is induced in more medial parts of the subventricular zone/intermediate zone and tangentially orientated CXCR4 neurons spread from lateral to the SDF-1-expressing region (Daniel et al. 2005, own unpublished observation, Fig. 1). In the late stage of cortical development, SDF1 expression is downregulated in the IZ/SVZ but maintained in the meninges. In parallel, CXCR4expressing neurons spread throughout all cortical layers and begin to adopt a radial orientation (Daniel

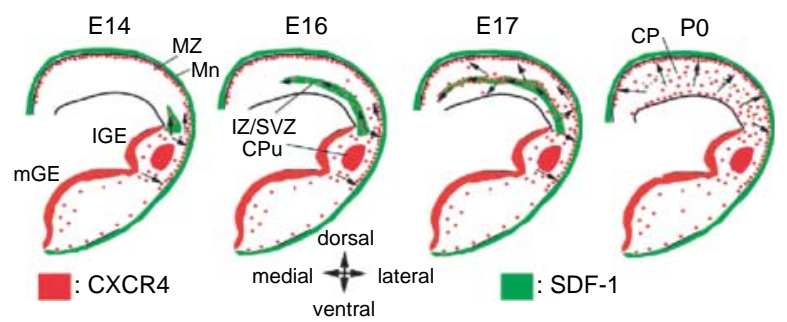

Figure 1 Schematic diagram summarizing patterns of SDF-1 and CXCR4 in the developing rat telencephalon. SDF-1 is shown in green and CXCR4 in red. The spatial orientation of migratory CXCR4-expressing neurons is symbolized by arrows. SDF-1 is expressed by cells in the leptomeninx $(\mathrm{Mn})$ at all developmental stages. At E14, a small area in the cortical intermediate zone/subventricular zone (IZ/SVZ) dorsal to the boundary of dorsal and ventral telencephalon expresses SDF-1. Until E17, SDF-1 is progressively upregulated in the dorsomedial part of the IZ/SVZ. Between E18 (not shown) and P0, SDF-1 is downregulated in the IZ/SVZ. At P0, slight expression of SDF-1 starts to become detectable in the cortical plate. CXCR4 is synthesized in the ventricular and subventricular zone of the lateral and medial ganglionic eminence as well as in projection neurons in the caudate-putamen (CPu). At E14, migratory CXCR4-expressing neurons populate the entire marginal zone and start to invade the IZ/SVZ. Until E17, tangentially migrating CXCR4-expressing neurons spread toward the dorsomedial edge of the IZ/SVZ. Ventrolaterally, CXCR4-expressing neurons migrate radially toward the meninges or tangentially toward the intermediate zone. Between E17 and P0, CXCR4-expressing neurons invade all cortical layers and assume a radial orientation in the cortex.

et al. 2005, own unpublished observation). Based on these patterns, it is tempting to propose that the gradual lateromedial spread of SDF-1 expression in the IZ/SVZ guides lateromedial tangential migration of CXCR4expressing neurons. Localization of SDF-1 in neuronal precursors in the cortical subventricular zone points to the possibility that pyramidal cell precursors use SDF-1 to instruct tangentially migrating GABAergic neurons originating in the ventral telencephalon (Tiveron $e t$ al. 2006). Remarkably, this mechanism is distinct from those in other brain regions, where mesenchymal cells secrete SDF-1 to regulate neuronal migration.

\section{SDF-1 isoforms and CXR4 in the postnatal and poststroke cerebral cortex}

Cortical SDF-1 expression continues to change significantly after birth. SDF-1 is gradually upregulated in pyramidal cells in deep cortical layers and blood vessels (Tham et al. 2001). Although the CXCR4 gene is silenced postnatally in most cortical neurons, still numerous cortical GABAergic neurons continue to express CXCR4 during the first 3 postnatal weeks (Stumm et al. 2003). During this period, contacts between cortical pyramidal cells and GABAergic neurons are established and refined. Given the fact 
that CXCR4 regulates axonal guidance in other neuronal systems (Chalasani et al. 2003, Lieberam et al. 2005), CXCR4 might be involved in the establishment of the cortical network.

In the adult cortex, the chief sites of SDF-1 mRNA expression are pyramidal cells as well as endothelial cells of few large and numerous small blood vessels (Tham et al. 2001, Stumm et al. 2002, 2003). Notably, SDF-1 isoforms are generated in a cell-selective manner. In cortex, SDF- $1 \alpha$ transcripts are generated in pyramidal cells and some large blood vessels, whereas SDF- $1 \beta / \gamma$ transcripts are generated in small blood vessels but not in neurons (Stumm et al. 2002). Since CXCR4 expression persists in distinct cortical neurons (Banisadr et al. 2002, Stumm et al. 2002, 2003), it is likely that SDF- $1 \alpha$ and CXCR4 exert a neuromodulatory role in cortical circuits.

In stroke models, CXCR4 expression is induced in numerous cortical neurons outside the primary lesion and neuronal SDF-1 expression is reduced (Stumm et al. 2002). This pattern is reminiscent of the early postnatal development stage and might reflect a state of enhanced plasticity. In addition, SDF-1 is upregulated in the infarcted tissue coincidently with numerous CXCR4-expressing cells including bone marrow-derived inflammatory cells appearing in the infarct (Stumm et al. 2002, Hill et al. 2004). Regarding the recruitment of circulating CXCR4-expressing cells to the brain, constitutive expression as well as pyrogen- and lesion-induced downregulation of SDF- $1 \beta / \gamma$ in endothelial cells might be of particular relevance (Stumm et al. 2002). This is emphasized by the fact that SDF-1 limits cerebral inflammation during experimental autoimmune encephalomyelitis by keeping CXCR4-expressing mononuclear cells in the perivascular space and thereby limiting parenchymal infiltration of autoreactive effector cells (McCandless et al. 2006).

CXCR4 is highly expressed throughout the ventricular system, in the olfactory bulb, and within the subgranular zone of the dentate gyrus (Lu et al. 2002, Stumm et al. 2002, 2003, Tissir et al. 2004), which are brain regions that are associated with adult neurogenesis. Expression of CXCR4 in neural progenitors has been shown only recently in the adult mouse brain (Tran et al. 2007). Moreover, SDF-1 has been reported to promote neuronal progenitor motility in the ischemic brain (Robin et al. 2006) and to direct the migration of new neurons toward sites of ischemic damage (Thored et al. 2006). Hence, scenarios in which the SDF-1/CXCR4 system appears to play a role in the adult cerebral cortex comprise neuromodulation in distinct cortical circuits, postlesional neuronal plasticity, neurogenesis and repair, as well as leukocyte recruitment and inflammation.

\section{Acknowledgements}

The authors declare that there is no conflict of interest that would prejudice the impartiality of this scientific work.

\section{References}

Alcantara S, Ruiz M, D’Arcangelo G, Ezan F, de Lecea L, Curran T, Sotelo C \& Soriano E 1998 Regional and cellular patterns of Reelin mRNA expression in the forebrain of the developing and adult mouse. Journal of Neuroscience 18 7779-7799.

Arakawa Y, Bito H, Furuyashiki T, Tsuji T, Takemoto-Kimura S, Kimura K, Nozaki K, Hashimoto N \& Narumiya S 2003 Control of axon elongation via an SDF-1alpha/Rho/mDia pathway in cultured cerebellar granule neurons. Journal of Cell Biology 161 381-391.

Bagri A, Gurney T, He X, Zou YR, Littman DR, Tessier-Lavigne M \& Pleasure SJ 2002 The chemokine SDF1 regulates migration of dentate granule cells. Development 129 4249-4260.

Banisadr G, Fontanges P, Haour F, Kitabgi P, Rostene W \& Melik Parsadaniantz S 2002 Neuroanatomical distribution of CXCR4 in adult rat brain and its localization in cholinergic and dopaminergic neurons. European Journal of Neuroscience 16 1661-1671.

Banisadr G, Skrzydelski D, Kitabgi P, Rostene W \& Parsadaniantz SM 2003 Highly regionalized distribution of stromal cell-derived factor1/CXCL12 in adult rat brain: constitutive expression in cholinergic, dopaminergic and vasopressinergic neurons. European Journal of Neuroscience 18 1593-1606.

Baudouin SJ, Pujol F, Nicot A, Kitabgi P \& Boudin H 2006 Dendriteselective redistribution of the chemokine receptor CXCR4 following agonist stimulation. Molecular and Cellular Neurosciences 33 160-169.

Belmadani A, Tran PB, Ren D, Assimacopoulos S, Grove EA \& Miller RJ 2005 The chemokine stromal cell-derived factor-1 regulates the migration of sensory neuron progenitors. Journal of Neuroscience 25 3995-4003.

Borrell V \& Marin O 2006 Meninges control tangential migration of hem-derived Cajal-Retzius cells via CXCL12/CXCR4 signaling. Nature Neuroscience 9 1284-1293.

Braun M, Wunderlin M, Spieth K, Knochel W, Gierschik P \& Moepps B 2002 Xenopus laevis Stromal cell-derived factor 1: conservation of structure and function during vertebrate development. Journal of Immunology 168 2340-2347.

Callewaere C, Banisadr G, Desarmenien MG, Mechighel P, Kitabgi P, Rostene WH \& Melik Parsadaniantz S 2006 The chemokine SDF1/CXCL12 modulates the firing pattern of vasopressin neurons and counteracts induced vasopressin release through CXCR4. PNAS 103 8221-8226.

Chalasani SH, Sabelko KA, Sunshine MJ, Littman DR \& Raper JA 2003 A chemokine, SDF-1, reduces the effectiveness of multiple axonal repellents and is required for normal axon pathfinding. Journal of Neuroscience 23 1360-1371.

Daniel D, Rossel M, Seki T \& Konig N 2005 Stromal cell-derived factor1 (SDF-1) expression in embryonic mouse cerebral cortex starts in the intermediate zone close to the pallial-subpallial boundary and extends progressively towards the cortical hem. Gene Expression Patterns 5 317-322.

Dickson BJ 2001 Rho GTPases in growth cone guidance. Current Opinion in Neurobiology 11 103-110.

Dickson BJ 2002 Molecular mechanisms of axon guidance. Science 298 1959-1964.

Dziembowska M, Tham TN, Lau P, Vitry S, Lazarini F \& Dubois-Dalcq M 2005 A role for CXCR4 signaling in survival and migration of neural and oligodendrocyte precursors. Glia 50 258-269. 
Forster E, Jossin Y, Zhao S, Chai X, Frotscher M \& Goffinet AM 2006 Recent progress in understanding the role of Reelin in radial neuronal migration, with specific emphasis on the dentate gyrus. European Journal of Neuroscience 23 901-909.

Hill WD, Hess DC, Martin-Studdard A, Carothers JJ, Zheng J, Hale D, Maeda M, Fagan SC, Carroll JE \& Conway SJ 2004 SDF-1 (CXCL12) is upregulated in the ischemic penumbra following stroke: association with bone marrow cell homing to injury. Journal of Neuropathology and Experimental Neurology 63 84-96.

Klein RS, Rubin JB, Gibson HD, DeHaan EN, Alvarez-Hernandez X, Segal RA \& Luster AD 2001 SDF-1 alpha induces chemotaxis and enhances Sonic hedgehog-induced proliferation of cerebellar granule cells. Development 128 1971-1981.

Kriegstein AR \& Noctor SC 2004 Patterns of neuronal migration in the embryonic cortex. Trends in Neurosciences 27 392-399.

Lazarini F, Casanova P, Tham TN, De Clercq E, Arenzana-Seisdedos F, Baleux F \& Dubois-Dalcq M 2000 Differential signalling of the chemokine receptor CXCR4 by stromal cell-derived factor 1 and the HIV glycoprotein in rat neurons and astrocytes. European Journal of Neuroscience 12 117-125.

Lieberam I, Agalliu D, Nagasawa T, Ericson J \& Jessell TM 2005 A Cxcl12-CXCR4 chemokine signaling pathway defines the initial trajectory of mammalian motor axons. Neuron 47 667-679.

Lu M, Grove EA \& Miller RJ 2002 Abnormal development of the hippocampal dentate gyrus in mice lacking the CXCR4 chemokine receptor. PNAS 99 7090-7095.

Ma Q Jones D, Borghesani PR, Segal RA, Nagasawa T, Kishimoto T, Bronson RT \& Springer TA 1998 Impaired B-lymphopoiesis, myelopoiesis, and derailed cerebellar neuron migration in CXCR4and SDF-1-deficient mice. PNAS 95 9448-9453.

Marchese A \& Benovic JL 2001 Agonist-promoted ubiquitination of the $\mathrm{G}$ protein-coupled receptor CXCR4 mediates lysosomal sorting. Journal of Biological Chemistry 276 45509-45512.

Marin O \& Rubenstein JL 2001 A long, remarkable journey: tangential migration in the telencephalon. Nature Reviews. Neuroscience 2 780-790.

McCandless EE, Wang Q, Woerner BM, Harper JM \& Klein RS 2006 CXCL12 limits inflammation by localizing mononuclear infiltrates to the perivascular space during experimental autoimmune encephalomyelitis. Journal of Immunology 177 8053-8064.

McQuibban GA, Butler GS, GongJH, Bendall L, Power C, Clark-Lewis I \& Overall CM 2001 Matrix metalloproteinase activity inactivates the CXC chemokine stromal cell-derived factor-1. Journal of Biological Chemistry 276 43503-43508.

van der Meer P, Ulrich AM, Gonzalez-Scarano F \& Lavi E 2000 Immunohistochemical analysis of CCR2, CCR3, CCR5, and CXCR4 in the human brain: potential mechanisms for HIV dementia. Experimental and Molecular Pathology 69 192-201.

Metin C, Baudoin JP, Rakic S \& Parnavelas JG 2006 Cell and molecular mechanisms involved in the migration of cortical interneurons. European Journal of Neuroscience 23 894-900.

Odemis V, Lamp E, Pezeshki G, Moepps B, Schilling K, Gierschik P, Littman DR \& Engele J 2005 Mice deficient in the chemokine receptor CXCR4 exhibit impaired limb innervation and myogenesis. Molecular and Cellular Neurosciences 30 494-505.

Paredes MF, Li G, Berger O, Baraban SC \& Pleasure SJ 2006 Stromalderived factor-1 (CXCL12) regulates laminar position of CajalRetzius cells in normal and dysplastic brains. Journal of Neuroscience 26 9404-9412.

Poznansky MC, Olszak IT, Foxall R, Evans RH, Luster AD \& Scadden DT 2000 Active movement of T cells away from a chemokine. Nature Medicine 6 543-548.

Pujol F, Kitabgi P \& Boudin H 2005 The chemokine SDF-1 differentially regulates axonal elongation and branching in hippocampal neurons. Journal of Cell Science 118 1071-1080.

Reiss K, Mentlein R, Sievers J \& Hartmann D 2002 Stromal cell-derived factor 1 is secreted by meningeal cells and acts as chemotactic factor on neuronal stem cells of the cerebellar external granular layer. Neuroscience 115 295-305.
Robin AM, Zhang ZG, Wang L, Zhang RL, Katakowski M, Zhang L, Wang Y, Zhang C \& Chopp M 2006 Stromal cell-derived factor lalpha mediates neural progenitor cell motility after focal cerebral ischemia. Journal of Cerebral Blood Flow and Metabolism 26 125-134.

Schwarting GA, Henion TR, Nugent JD, Caplan B \& Tobet S 2006 Stromal cell-derived factor-1 (chemokine C-X-C motif ligand 12) and chemokine C-X-C motif receptor 4 are required for migration of gonadotropin-releasing hormone neurons to the forebrain. Journal of Neuroscience 26 6834-6840.

Soriano E \& Del Rio JA 2005 The cells of Cajal-Retzius: still a mystery one century after. Neuron 46 389-394.

Stumm RK, Rummel J, Junker V, Culmsee C, Pfeiffer M, Krieglstein J, Hollt V \& Schulz S 2002 A dual role for the SDF-1/CXCR4 chemokine receptor system in adult brain: isoform-selective regulation of SDF-1 expression modulates CXCR4-dependent neuronal plasticity and cerebral leukocyte recruitment after focal ischemia. Journal of Neuroscience 22 5865-5878.

Stumm RK, Zhou C, Ara T, Lazarini F, Dubois-Dalcq M, Nagasawa T, Hollt V \& Schulz S 2003 CXCR4 regulates interneuron migration in the developing neocortex. Journal of Neuroscience 23 5123-5130.

Takiguchi-Hayashi K, Sekiguchi M, Ashigaki S, Takamatsu M, Hasegawa H, Suzuki-Migishima R, Yokoyama M, Nakanishi S \& Tanabe Y 2004 Generation of Reelin-positive marginal zone cells from the caudomedial wall of telencephalic vesicles. Journal of Neuroscience 24 2286-2295.

Tanaka E \& Sabry J 1995 Making the connection: cytoskeletal rearrangements during growth cone guidance. Cell 83 171-176.

Tham TN, Lazarini F, Franceschini IA, Lachapelle F, Amara A \& Dubois-Dalcq M 2001 Developmental pattern of expression of the alpha chemokine stromal cell-derived factor 1 in the rat central nervous system. European Journal of Neuroscience 13 845-856.

Thored P, Arvidsson A, Cacci E, Ahlenius H, Kallur T, Darsalia V, Ekdahl CT, Kokaia Z \& Lindvall O 2006 Persistent production of neurons from adult brain stem cells during recovery after stroke. Stem Cells 24 739-747.

Tissir F, Wang CE \& Goffinet AM 2004 Expression of the chemokine receptor CXCR4 mRNA during mouse brain development. Brain Research. Developmental Brain Research 149 63-71.

Tiveron MC, Rossel M, Moepps B, Zhang YL, Seidenfaden R, Favor J, Konig N \& Cremer H 2006 Molecular interaction between projection neuron precursors and invading interneurons via stromal-derived factor 1 (CXCL12)/CXCR4 signaling in the cortical subventricular zone/intermediate zone. Journal of Neuroscience 26 13273-13278.

Tran PB, Banisadr G, Ren D, Chenn A \& Miller RJ 2007 Chemokine receptor expression by neural progenitor cells in neurogenic regions of mouse brain. Journal of Comparative Neurology $\mathbf{5 0 0}$ $1007-1034$.

Vilz TO, Moepps B, Engele J, Molly S, Littman DR \& Schilling K 2005 The SDF-1/CXCR4 pathway and the development of the cerebellar system. European Journal of Neuroscience 22 1831-1839.

Yamazaki H, Sekiguchi M, Takamatsu M, Tanabe Y \& Nakanishi S 2004 Distinct ontogenic and regional expressions of newly identified Cajal-Retzius cell-specific genes during neocorticogenesis. PNAS 101 14509-14514.

Zhu Y, Yu T, Zhang XC, Nagasawa T, Wu JY \& Rao Y 2002 Role of the chemokine SDF-1 as the meningeal attractant for embryonic cerebellar neurons. Nature Neuroscience 5 719-720.

Zou YR, Kottmann AH, Kuroda M, Taniuchi I \& Littman DR 1998 Function of the chemokine receptor CXCR4 in haematopoiesis and in cerebellar development. Nature 393 595-599.

Received in final form 22 January 2007

Accepted 22 January 2007

Made available online as an Accepted Preprint 23 January 2007 